\title{
Brief comments on three existing approaches for managing neonates at risk of early-onset sepsis
}

\author{
E. Vaccina ${ }^{1}$, A. Luglio ${ }^{1}$, M. Ceccoli', M. Lecis ${ }^{1}$, F. Leone ${ }^{1}$, T. Zini' ${ }^{1}$, G. Toni ${ }^{1}$, L. Lugli ${ }^{2}$, L. Lucaccioni ${ }^{3}$, L. lughetti ${ }^{3}$ and \\ A. Berardi ${ }^{2 *}$ (D)
}

\begin{abstract}
Background: Growing concerns regarding the adverse effects of antibiotics during the first days of life and the marked reduction in the incidence of early-onset sepsis (EOS) are changing the clinical practice for managing neonates at risk of EOS. Strategies avoiding unnecessary antibiotics while promoting mother-infant bonding and breastfeeding deserve to be considered.

Main body: We compare strategies for managing newborns at risk of EOS recommended by the American Academy of Pediatrics, which are among the most followed recommendations worldwide. Currently three different approaches are suggested in asymptomatic full-term or late preterm neonates: i) the conventional management, based on standard perinatal risk factors for EOS alone, ii) the neonatal sepsis calculator, a multivariate risk assessment based on individualized, quantitative risk estimates (relying on maternal risk factors for EOS) combined with physical examination findings at birth and in the following hours and iii) an approach entirely based on newborn clinical condition (serial clinical observation) during the first $48 \mathrm{~h}$ of life.

We discuss advantages and limitations of these approaches, by analyzing studies supporting each strategy. Approximately $40 \%$ of infants who develop EOS cannot be identified on the basis of maternal RFs or laboratory tests, therefore close monitoring of the asymptomatic but at-risk infant remains crucial. A key question is to know what proportion of babies with mild, unspecific symptoms at birth can be managed safely without giving antibiotics.
\end{abstract}

Conclusions: Both neonatal sepsis calculator and serial clinical observation may miss cases of EOS, and clinical vigilance for all neonates is essential There is a need to assess which symptoms at birth are more predictive of EOS, and therefore require immediate interventions, or symptoms that can be carefully reevaluated without necessarily treat immediately the neonate with antibiotics. Studies comparing strategies for managing neonates are recommended.

Keywords: Newborn, Early-onset sepsis, Group B streptococcus, Prevention, Serial clinical observation, Neonatal Sepsis calculator, Intrapartum antibiotic prophylaxis

\footnotetext{
* Correspondence: alberto.berardi@unimore.it

${ }^{2}$ Neonatal Intensive Care Unit, Department of Medical and Surgical Sciences

of the Mothers, Children and Adults, University of Modena and Reggio

Emilia, via del Pozzo 71, 41124 Modena, Italy

Full list of author information is available at the end of the article
}

(c) The Author(s). 2021 Open Access This article is licensed under a Creative Commons Attribution 4.0 International License, which permits use, sharing, adaptation, distribution and reproduction in any medium or format, as long as you give appropriate credit to the original author(s) and the source, provide a link to the Creative Commons licence, and indicate if changes were made. The images or other third party material in this article are included in the article's Creative Commons licence, unless indicated otherwise in a credit line to the material. If material is not included in the article's Creative Commons licence and your intended use is not permitted by statutory regulation or exceeds the permitted use, you will need to obtain permission directly from the copyright holder. To view a copy of this licence, visit http://creativecommons.org/licenses/by/4.0/. The Creative Commons Public Domain Dedication waiver (http://creativecommons.org/publicdomain/zero/1.0/) applies to the data made available in this article, unless otherwise stated in a credit line to the data. 


\section{Background}

Early onset sepsis (EOS) is sepsis presenting from 0 to $72 \mathrm{~h}$ of life [1,2]. Although its current incidence is lower than in the past [3], EOS is still a problem. Non-specific clinical presentation and low predictive values of common biomarkers complicate the early diagnosis [2], that is essential to prevent life threatening complications. Antibiotics are often given in suspected EOS, but unnecessary antibiotics have potential adverse consequences [4, 5]. The approach for managing neonates at risk of EOS is controversial [1].

\section{Main body}

\section{Conventional management (CM)}

Standard perinatal RFs alone are insufficient for ascertainment of neonatal EOS. Indeed, current diagnostic tests are poorly predictive of EOS in asymptomatic neonates, resulting in unnecessary evaluations and antibiotic exposure for numerous uninfected neonates [2]. In fact, up to $15 \%$ of infants are evaluated for EOS, and approximately half of them receive empiric antibiotic treatment for rule out EOS [6].

\section{The neonatal sepsis calculator (NSC)}

A multivariate risk assessment has been developed by Kaiser Permanent Northern California (CA, USA). Individualized, quantitative risk estimates (based on maternal RFs) are combined with physical examination findings. According to perinatal information such as gestational age, duration of membrane rupture, highest maternal temperature during labour, GBS colonization status, intrapartum antibiotic prophylaxis (IAP) and clinical conditions in the first $12 \mathrm{~h}$ of life (well appearing, equivocal, or clinically ill, Table 1) a sepsis risk score was developed [8].
The RFs based logistic regression model was developed by using a nested case-control study performed at 14 US centers. This large study included data from 608,014 neonates with $\geq 34$ weeks' gestation born in the period between 1993 and 2007 [9]. Cases of EOS $(n=350)$ were defined as isolation of a pathogen (or a contaminant treated with antibiotics for at least 5 days) in blood or CSF culture within $72 \mathrm{~h}$ of birth, regardless of the presence of symptoms. Furthermore, investigators randomly selected 1063 controls from the birth cohort, and each case of EOS was matched with three controls. The most predictive factors for EOS were lower gestational age and higher intrapartum maternal temperature, which accounted for 17 and $58 \%$ of the model's predictive ability, respectively. However, $32 \%$ of neonates in the initial cohort with positive blood cultures were asymptomatic, a finding that may potentially overestimate the risk of EOS in the regression model. NSC was updated in 2014 [10] to incorporate into the risk stratification algorithm the results of physical examination (well appearing, equivocal presentation and clinical illness) until the first $24 \mathrm{~h}$ of life. For each category of disease, likelihood ratios were identified which, when combined with the risk of sepsis at birth (based on RFs alone), generated a posttest probability of EOS by dividing newborns into 3 risk layers $(<0.65,0.65-1.54$ and $>1.54$ cases $/ 1000$ live births, respectively). The clinical presentation had effects on the posterior probability for a given EOS risk at birth (likelihood ratio $0.41,5.0$ and 21.2 for well appearing, equivocal and clinical illness, respectively). For each infant the NSC estimated the individual risk of EOS. A posterior risk of EOS $<1,1-3$ and $>3 / 1000$ live births indicated different recommendations (observation, evaluation or antibiotic treatment) [11].

Table 1 Classification of Infant's Clinical Presentation according to NSC (available at https://neonatalsepsiscalculator. kaiserpermanente.org/) [7]

\begin{tabular}{|c|c|}
\hline Clinical Exam & Description \\
\hline Clinical Illness & $\begin{array}{l}\text { 1. Persistent need for NCPAP / HFNC / mechanical ventilation (outside of the delivery room) } \\
\text { 2. Hemodynamic instability requiring vasoactive drugs } \\
\text { 3. Neonatal encephalopathy /Perinatal depression } \\
\text { - Seizure } \\
\text { - Apgar Score at } 5 \text { min }<5 \\
\text { 4. Need for supplemental O } 2>2 \text { h to maintain oxygen saturations }>90 \% \text { (outside of the delivery room) }\end{array}$ \\
\hline Equivocal & $\begin{array}{l}\text { 1. Persistent physiologic abnormality }>4 \mathrm{~h} \\
\text { - Tachycardia (HR }>160) \\
\text { - Tachypnea (RR }>60) \\
\text { - Temperature instability ( }>100.4^{\circ} \mathrm{F} \text { or }<97.5^{\circ} \mathrm{F} \text { ) } \\
\text { - Respiratory distress (grunting, flaring, or retracting) not requiring supplemental } \mathrm{O} 2 \\
\text { 2. Two or more physiologic abnormalities lasting for }>2 \mathrm{~h} \\
\text { - Tachycardia ( } \mathrm{HR}>160) \\
\text { - Tachypnea (RR }>60) \\
\text { - Temperature instability ( }>100.4^{\circ} \mathrm{F} \text { or }<97.5^{\circ} \mathrm{F} \text { ) } \\
\text { - Respiratory distress (grunting, flaring, or retracting) not requiring supplemental } \mathrm{O} 2 \\
\text { Note: abnormality can be intermittent }\end{array}$ \\
\hline Well Appearing & No persistent physiologic abnormalities \\
\hline
\end{tabular}


However, in the determination of the final risk, the developers of the model attributed an a priori greater relevance to symptoms, although in absence of strong evidences [12]. Symptoms defined as "equivocal" or "clinical illness" are common in the first hours of life, due to transition to extrauterine life. Developers of NSC introduced safeguards to not discontinue ("strongly consider") antibiotics in infants with clinical symptoms, even if the posterior probability was below the threshold for treatment ( $<3$ cases/1000 live births) [11]. This recommendation would increase antibiotic exposure in uninfected infants [12].

\section{Comparisons between NSC and CM}

A systematic review and meta-analysis of published before-after studies regarding NSC [13] included 13 relevant studies and analyzed a total of 175,752 infants. With respect to CM guided strategies, NSC was associated with a reduction in empiric antibiotic use for suspected EOS [relative risk of antibiotic use of 56, 95\% C.I. 53-59\%]. Rates of missed cases of EOS (defined as an antibiotic initiated after $24 \mathrm{~h}$ of life in neonates with culture-positive EOS) were comparable (NSC: $28 \%$ vs. CM: 29\%, pooled odds ratio, 0.96; 95\% C.I., $0.26-3.52 ; P=0.95)$. However, NSC does not provide accurate risk estimates with regard to absolute risk of EOS in newborn babies. Estimates might be compromised by technical issues arising with the development and adaptation of the NSC prediction algorithm [12].

\section{Serial clinical observation (SCO)}

An approach entirely based on newborn clinical condition during the first hours of life has recently gained consensus [14, 15]. Asymptomatic neonates undergo a standardized observation (by midwives, nurses and physicians) in the first $48 \mathrm{~h}$ of life (Table 2). Laboratory evaluation or empirical antibiotic treatment are only initiated if clinical signs of illness develop [16].

A retrospective cohort study at a single Italian centre (20,401 live births from 2005 to 2011) [14] compared a random sample of 500 neonates managed according to $\mathrm{CM}$ and 500 neonates managed through SCO. Investigators reported significant reduction of laboratory tests (from 11.6 to $1.6 \%, P<0.01$ ) and empirical antibiotics (from 2.8 to $0.6 \%, \mathrm{P}<0.01$ ) following an SCO approach. By reviewing cases of EOS occurring in both periods investigators found no evidence of delayed antibiotic administration or increased risk of neonates to be readmitted for EOS after discharge from hospital. However, the initial symptoms triggering laboratory evaluation or antibiotic therapy were poorly standardized in the original SCO approach, and there was heterogeneity among centers in the timing and ways of performing SCO. This strategy has been recently updated [16, 17].

Minor and major clinical symptoms and criteria most suggestive of EOS during the first hours of life have been recently defined (Table 3 ).

SCO recommends observation (without empirical antibiotics) for most neonates with mild, nonspecific symptoms (even in the presence of RFs). Such symptoms are quite different from those suggested by the NSC. Thus,

Table 2 Serial clinical observation approach recommended in Emilia-Romagna (Italy) (modified with permission from ref. [16]). Clinical observation record sheet and timing of visits

\begin{tabular}{|c|c|c|c|c|c|}
\hline Hours of life & Signature \& & $\begin{array}{l}\text { General } \\
\text { wellbeing, } \\
\text { Reactivity, } \\
\text { Spontaneous } \\
\text { motility } \\
\text { (Yes/No) }\end{array}$ & $\begin{array}{l}\text { Skin colour } \\
\text { Skin color } \\
\mathrm{N}=\text { Normal } \\
\mathrm{P}=\text { Pale } \\
\mathrm{M}=\text { Marbled } \\
\mathrm{C}=\text { Cyanotic }\end{array}$ & $\begin{array}{l}\text { Respiratory rate } \\
\text { (breaths/minutes) }\end{array}$ & $\begin{array}{l}\text { Respiratory } \\
\text { distress } \\
\text { syndrome } \\
\text { (Yes/No) }\end{array}$ \\
\hline $1 \mathrm{hrs}$ & & & & & \\
\hline $3 \mathrm{hrs}$ & & & & & \\
\hline $6 \mathrm{hrs}$ & & & & & \\
\hline $12 \mathrm{hrs}$ & & & & & \\
\hline $18( \pm 2)$ hrs & & & & & \\
\hline $24( \pm 2)$ hrs & & & & & \\
\hline $36( \pm 2)$ hrs & & & & & \\
\hline $46( \pm 2)$ hrs & & & & & \\
\hline
\end{tabular}


Table 3 Minor and major clinical symptoms and criteria suggesting observation or laboratory evaluation and antibiotic treatment

\begin{tabular}{|c|c|}
\hline Minor $\neq$ & Major \\
\hline $\begin{array}{l}\text { Mild respiratory distress (> } 60 \mathrm{bpm} \text { ) without the need of } \\
\text { respiratory support }\end{array}$ & $\begin{array}{l}\text { Moderate to severe respiratory distress (requiring respiratory support) } \S \rightarrow \text { tachypnoea } \\
\text { plus increased respiratory effort }\end{array}$ \\
\hline Tachycardia > 160 bpm & Hypoxia, reduced SpO2 saturation \\
\hline Metabolic acidosis (base excess $\leq-10 \mathrm{mmol} / \mathrm{lt}$ ) & $\begin{array}{l}\text { Reduced skin perfusion, Refill time } \geq 3 " \\
\text { Signs of shock }\end{array}$ \\
\hline \multirow[t]{3}{*}{ Temperature $<36^{\circ}$ or $>37.5<38^{\circ} \mathrm{C}$} & Temperature $\geq 38^{\circ} \mathrm{C}$ \\
\hline & Greyish, pallor or marbling of the skin colour \\
\hline & Worsening of general wellbeing, apnoea, lethargy, irritability, convulsions \\
\hline
\end{tabular}

\section{$\mathrm{SpO2}$, Saturation of peripheral oxygen}

$\neq$ On the basis of the clinician's judgment laboratory evaluation can be delayed in the presence of minor, initial, unspecific and non-progressive symptoms during the first 12-24 h of life. Neonates with mild symptoms are re-evaluated at 2-h intervals. The presence of major symptoms, the worsening or persistence (for 12$24 \mathrm{~h}$ ) of minor symptoms suggest laboratory evaluation and (eventually) empirical antibiotics, but the decision is left to the clinician's discretion $\S$ respiratory support includes mechanical ventilation and nasal continuous positive airway pressure. However, it does not necessarily include high flow nasal cannula

the use of empirical antibiotics is likely to be different. The safety of this updated SCO strategy is under evaluation.

As with the NSC strategy, cases of EOS may be missed with SCO if neonates are selected only on the basis of maternal RFs. A large, multicenter study in Italy reported 48 cases of confirmed group B streptococcus EOS among 265,508 live births managed through an SCO approach; 15 of 48 cases (31.2\%) had no RFs for EOS and had symptoms of EOS (three had severe disease) during their hospitalization. Most of them $(n=12)$ were well appearing at birth but subsequently developed symptoms [18].

\section{Comparisons between NSC and SCO}

A retrospective study [19] addressed both safety and empiric antibiotic use for suspected EOS after an SCO or NSC guided approach. Investigators analyzed a cohort of 384 infants of gestational age $\geq 34$ weeks undergoing antibiotic therapy in the first $72 \mathrm{~h}$ of life. While no cases of EOS would have been missed with both strategies, newborns who would have received antibiotics according to SCO or NSC were 17 and $57 \%(p<0.001)$ respectively. However, the selection of neonates for antibiotic treatment was decided a posteriori, after the newborns had already been managed by the clinician.

\section{Conclusions}

Both NSC and SCO may miss cases of EOS, and clinical vigilance for all neonates is essential. Furthermore, unnecessary antibiotics would be reduced by identifying symptoms more predictive of EOS. Studies comparing strategies for managing neonates are recommended.

\section{Abbreviations}

EOS: Early-onset sepsis; RFs: Risk factors; NSC: Neonatal sepsis calculator; IAP: Intrapartum antibiotic prophylaxis; SCO: Serial clinical observation

\section{Acknowledgments}

Not applicable.

\section{Financial disclosure}

Prof. Alberto Berardi has not received fees.

\section{Authors' contributions}

$A B, E V$ and $A L$ drafted the initial manuscript, reviewed, revised, and approved the final manuscript as submitted. $A B$ and EV designed the data collection instruments, drafted the initial manuscript, reviewed, revised, and approved the final manuscript as submitted. They conceptualized and designed the study, critically reviewed the manuscript, and approved the final manuscript as submitted. All authors approved the final manuscript as submitted and agree to be accountable for all aspects of the work.

\section{Availability of data and materials}

Not applicable.

\section{Declarations}

Ethics approval and consent to participate

Prot $N^{\circ}$ 0019112/19 del 03/07/2019.

\section{Consent for publication}

Not applicable.

\section{Competing interests}

The authors declare that they have no competing interests.

The authors declare they have no funding source.

\section{Author details}

${ }^{1}$ Post Graduate School of Paediatrics, Department of Medical and Surgical Sciences of the Mothers, Children and Adults, University of Modena and Reggio Emilia, via del Pozzo 71, 41124 Modena, Italy. ${ }^{2}$ Neonatal Intensive Care Unit, Department of Medical and Surgical Sciences of the Mothers, Children and Adults, University of Modena and Reggio Emilia, via del Pozzo 71, 41124 Modena, Italy. ${ }^{3}$ Pediatric Unit, Department of Medical and Surgical Sciences of the Mothers, Children and Adults, University of Modena and Reggio Emilia, via del Pozzo 71, 41124 Modena, Italy.

Received: 25 January 2021 Accepted: 15 June 2021

Published online: 18 July 2021

\section{References}

1. Puopolo KM, Benitz WE, Zaoutis TE, Committee on fetus and newborn, Committee on Infectious Diseases. Management of Neonates Born at $\geq 35$ 0/7 weeks' gestation with suspected or proven early-onset bacterial Sepsis. Pediatrics. 2018;142(6):e20182894. https://doi.org/10.1542/peds.2018-2894. 
2. Benitz WE, Wynn JL, Polin RA. Reappraisal of guidelines for Management of Neonates with suspected early-onset Sepsis. J Pediatr. 2015;166(4):1070-4. https://doi.org/10.1016/j.jpeds.2014.12.023.

3. Kuzniewicz MW, Puopolo KM, Fischer A, Walsh EM, Li S, Newman TB, et al. A quantitative, risk-based approach to the management of neonatal earlyonset Sepsis. JAMA Pediatr. 2017;171(4):365-71. https://doi.org/10.1001/jama pediatrics.2016.4678.

4. Ficara M, Pietrella E, Spada C, Della Casa Muttini E, Lucaccioni L, lughetti L, et al. Changes of intestinal microbiota in early life. J Matern Fetal Neonatal Med. 2020;33(6):1036-43. https://doi.org/10.1080/14767058.2018.1506760.

5. Benitz WE, Long SS. The holy grail of ascertainment of early-onset neonatal Sepsis. J Pediatr. 2019;213:10-2. https://doi.org/10.1016/j.jpeds.2019.05.072.

6. Mukhopadhyay S, Eichenwald EC, Puopolo KM. Neonatal early-onset sepsis evaluations among well-appearing infants: projected impact of changes in CDC GBS quidelines. J Perinatol. 2013;33(3):198-205. https://doi.org/10.1038/ jp.2012.96.

7. Kaiser Permanente Division of Research. Neonatal Early-Onset Sepsis Calculator. 2021. Available from: https://neonatalsepsiscalculator.kaiserperma nente.org/

8. Puopolo KM, Draper D, Wi S, Newman TB, Zupancic J, Lieberman E, et al. Estimating the probability of neonatal early-onset infection on the basis of maternal risk factors. Pediatrics. 2011;128(5):e1155-63. https://doi.org/10.1 542/peds.2010-3464

9. Puopolo KM, Escobar GJ. Early-onset sepsis: a predictive model based on maternal risk factors. Curr Opin Pediatr. 2013;25(2):161-6. https://doi.org/10.1 097/MOP.0b013e32835e1f96.

10. Escobar GJ, Puopolo KM, Wi S, Turk BJ, Kuzniewicz MW, Walsh EM, et al. Stratification of risk of early-onset Sepsis in newborns $\geq 34$ weeks' gestation. Pediatrics. 2014;133(1):30-6. https://doi.org/10.1542/peds.2013-1689.

11. Kuzniewicz MW, Walsh EM, Li S, Fischer A, Escobar GJ. Development and implementation of an early-onset Sepsis calculator to guide antibiotic Management in Late Preterm and Term Neonates. Jt Comm J Qual Patient Saf. 2016;42(5):232-9. https://doi.org/10.1016/S1553-7250(16)42030-1.

12. Benitz WE, Achten NB. Technical assessment of the neonatal early-onset sepsis risk calculator. Lancet Infect Dis. 2020:S1473309920304904.

13. Achten NB, Klingenberg C, Benitz WE, Stocker M, Schlapbach LJ, Giannoni E, et al. Association of Use of the Neonatal Early-Onset Sepsis Calculator With Reduction in Antibiotic Therapy and Safety: A Systematic Review and Metaanalysis. JAMA Pediatr. 2019;173(11):1032.

14. Joshi NS, Gupta A, Allan JM, Cohen RS, Aby JL, Weldon B, et al. Clinical monitoring of well-appearing infants born to mothers with Chorioamnionitis. Pediatrics. 2018;141(4):e20172056. https://doi.org/10.1542/ peds.2017-2056.

15. Berardi A, Fornaciari S, Rossi C, Patianna V, Bacchi Reggiani ML, Ferrari F, et al. Safety of physical examination alone for managing well-appearing neonates $\geq 35$ weeks' gestation at risk for early-onset sepsis. J Matern Fetal Neonatal Med. 2015;28(10):1123-7. https://doi.org/10.3109/14767058.2014.946499.

16. Berardi A, Bedetti L, Spada C, Lucaccioni L, Frymoyer A. Serial clinical observation for management of newborns at risk of early-onset sepsis. Curr Opin Pediatr. 2020;32(2):245-51. https://doi.org/10.1097/MOP. 0000000000000864

17. Berardi A, Spada C, Ciccia M, et al. Observation of the newborn at risk of early-onset sepsis: the approach of the region Emilia-Romagna (Italy). Medico e Bambino. 2019;38:370-6.

18. Berardi A, Spada C, Reggiani MLB, Creti R, Baroni L, Capretti MG, et al. Group B Streptococcus early-onset disease and observation of well-appearing newborns. Simeoni U, editor. PLoS ONE. 2019;14(3):e0212784.

19. Benincasa BC, Silveira RC, Schlatter RP, Balbinotto Neto G, Procianoy RS. Multivariate risk and clinical signs evaluations for early-onset sepsis on late preterm and term newborns and their economic impact. Eur J Pediatr. 2020;179(12):1859-65. https://doi.org/10.1007/s00431-020-03727-z.

\section{Publisher's Note}

Springer Nature remains neutral with regard to jurisdictional claims in published maps and institutional affiliations.

Ready to submit your research? Choose BMC and benefit from:

- fast, convenient online submission

- thorough peer review by experienced researchers in your field

- rapid publication on acceptance

- support for research data, including large and complex data types

- gold Open Access which fosters wider collaboration and increased citations

- maximum visibility for your research: over $100 \mathrm{M}$ website views per year

At $\mathrm{BMC}$, research is always in progress.

Learn more biomedcentral.com/submissions 